\title{
Bispectral index and cerebral oximetry in low-flow and high-flow rate anaesthesia during laparoscopic cholecystectomy - a randomized controlled trial
}

\author{
Jacek Kupisiak ${ }^{1}$, Robert Goch ${ }^{1}$, Wojciech Polenceusz ${ }^{1}$, Robert Szyca2,3, Krzysztof Leksowski2,3 \\ 1Department of Anaesthesiology, Military Clinical Hospital, Bydgoszcz, Poland \\ 2Department of General, Thoracic and Vascular Surgery, Military Clinical Hospital, Bydgoszcz, Poland \\ ${ }^{3}$ Chair of Public Health, Collegium Medicum of Nicolaus Copernicus University, Bydgoszcz, Poland
}

\begin{abstract}
Introduction: The need to reduce pollution emissions in the operating room and to reduce treatment costs motivates more frequent use of general anaesthesia with a small or minimal fresh gas flow rate. Nevertheless, the reduction of the delivery of fresh gases should not influence the quality and safety of the anaesthesia.

Material and methods: A total of 105 elective laparoscopic cholecystectomy patients were included in the study. There were 72 female (68.6\%) and 33 male (31.4\%) patients. Patients were randomized by a 'closed envelope' method into two groups. Group I included patients with low-flow anaesthesia and group II included patients with high-flow anaesthesia. In all patients the cerebral oximetry was measured separately for each cerebral hemisphere; the bispectral index (BIS), heart rate, blood pressure, end-tidal carbon dioxide concentration and haemoglobin oxygen saturation were monitored.

Results: Heart rate, blood pressure, end-tidal carbon dioxide concentration and saturation were similar in both groups and the differences between them were statistically insignificant. The BIS values were similar in both groups and indicated that patients who underwent low-flow anaesthesia were not exposed to a higher risk of awakening during the procedure than the high-flow anaesthesia patients. The changes in brain oximetry values were similar in both lowflow and high-flow anaesthesia.

Conclusions: Use of both low-flow and high-flow rate general anaesthesia provided patients undergoing laparoscopic cholecystectomy proper oxygenation of the central nervous system, adequate sleep depth and haemodynamic stability.
\end{abstract}

Key words: laparoscopic cholecystectomy, oximetry, bispectral index, low-flow anaesthesia.

\section{Introduction}

Cholecystectomy remains the most frequent laparoscopic procedure and the most popular mode of general anaesthesia used for this procedure is bal- anced anaesthesia with the use of fresh gases at a high flow of $6 \mathrm{l} / \mathrm{min}$. The need to reduce pollution emissions in the operating room and to reduce treatment costs motivates more frequent use of general 
anaesthesia with small (0.5-1 l/min) or minimal (up to $0.5 \mathrm{l} / \mathrm{min}$ ) fresh gas flow rates, especially when using such expensive resources as desflurane and isoflurane [1-6]. Insufflation of the abdominal cavity with $\mathrm{CO}_{2}$ during laparoscopy results in the increase of intra-abdominal pressure, reduction of functional residual capacity (FRC), decrease of pulmonary compliance, hypercapnia and increase of the systemic vascular resistance (SVR). All above factors together with Trendelenburg's position can cause a difficultto-estimate increase of the intracranial pressure and reduction in the cerebral blood flow (CBF) and as a consequence cerebral hypoxia [5]. One way to avoid these problems might be the use of low-flow rate anaesthesia (LFA) during laparoscopic operations $[4,6]$. Nevertheless, reduction of the fresh gas delivery should not influence the quality and safety of the anaesthesia.

\section{Aim}

The aim of this study was to compare the influence of low-flow and high-flow general anaesthesia on the oxygenation of the central nervous system and sleep depth in patients subjected to laparoscopic cholecystectomy.

\section{Material and methods}

Hundred and five patients participated in this prospective randomized study: 72 females (68.6\%) and 33 males (31.4\%) with mean age of 52 years (range 20-82 years). The closed envelope randomization method was used. Patients were randomly allocated to one of the two groups. Group I - low-flow anaesthesia with $0.8 \mathrm{l} / \mathrm{min}$ fresh gas flow rate $\left(0.4 \mathrm{l} / \mathrm{min} \mathrm{O}_{2}\right.$ and $0.4 \mathrm{l} / \mathrm{min}$ air) in the closed circuit and sevoflurane up to the value of 1 minimal alveolar concentration (MAC) in the exhaled air. Fifty-one patients were assigned to this group: 40 females (78.4\%) and 11 males (21.6\%), aged 20-79 years-old (mean 50.4 years). Group II - high-flow anaesthesia with $6 \mathrm{l} / \mathrm{min}$ fresh gases flow rate (4l of air and $2 \mathrm{I}$ of $\mathrm{O}_{2}$ ) in the closed circuit and sevoflurane up to the value of $1 \mathrm{MAC}$ in the exhaled air. Fifty-four patients were assigned to this group with 32 females (59.3\%) and 22 males (40.7\%) with mean age of 53.5 years (range 27-82 years).

Age-related MAC values were assessed and expressed as volume percentage. Ventilation parameters were adjusted to maintain the end-tidal $\mathrm{CO}_{2}$ $\left(\mathrm{ETCO}_{2}\right)$ of $35-45 \mathrm{mmHg}$. Muscle relaxants were admi- nistered depending on the number of train-of four (TOF) responses. The TOF responses were evaluated by ulnar nerve stimulation and corresponding response of the adductor muscle of the thumb. Nitrous oxide was not used in either group during the anaesthesia. To adjust for the peritoneal cavity $\mathrm{CO}_{2}$ insufflation the induction period of anaesthesia was reduced to $5 \mathrm{~min}$.

In all patients cerebral oximetry was performed separately for each cerebral hemisphere using noninvasive near infrared spectroscopy (NIRS) - system INVOS 4100 Cerebral Oximeter (Somanetics Corporation, Troy, MI). The bispectral index was also monitored using the electrode with four leads placed on the patient's forehead (Datex-Ohmeda). Moreover, in all patients heart rate $(\mathrm{HR})$, arterial blood pressure (BP), end-tidal $\mathrm{CO}_{2}$ concentration $\left(\mathrm{ETCO}_{2}\right)$ and haemoglobin oxygen saturation $\left(\mathrm{SatO}_{2}\right)$ were recorded. The measurements were taken at the following time points: before induction, during passive oxygenation, during intubation, directly after intubation, during $\mathrm{CO}_{2}$ insufflation of the abdominal cavity, during gallbladder exteriorization, directly before, during and after recovery. Anaesthetization time was also measured for both groups. Patients with neurological disorders, impaired cerebral circulation, arterial vessel disorders, after brain strokes and patients abusing alcohol or psychoactive substances were excluded from the study. Furthermore, patients who required changes to the randomly assigned mode of anaesthesia were disqualified.

Correlation analysis was based on the calculation of Spearman's rank correlation coefficients. Value of $p$ below 0.05 was considered as statistically significant. Consent to conduct the study was obtained from the Bioethical Committee of the Medical University of Lodz.

\section{Results}

The mean total time of the anaesthesia was 69.5 min (range 50-105 $\mathrm{min}$ ) in group I and $77.3 \mathrm{~min}$ (range 45-150 $\mathrm{min}$ ) in group II. There was no statistically significant difference in the anaesthesia time between the groups $(p>0.05)$.

Heart rate (HR), arterial blood pressure (BP), endtidal $\mathrm{CO}_{2}$ concentration $\left(\mathrm{ETCO}_{2}\right)$ and haemoglobin oxygen saturation $\left(\mathrm{SaO}_{2}\right)$ were similar for both groups and the differences did not reach statistical significance (Table I). Patients with low-flow rate anaesthesia were not exposed to higher risk of awakening during the operation than the patients 
Table I. A comparison of heart rate (HR), blood pressure (BP) end-tidal concentration of carbon dioxide $\left(\mathrm{ETCO}_{2}\right)$ and haemoglobin oxygen saturation

\begin{tabular}{|c|c|c|c|c|c|c|c|c|c|c|c|}
\hline \multirow[t]{3}{*}{ Time } & \multicolumn{5}{|c|}{ Group I } & \multicolumn{5}{|c|}{ Group II } & \multirow{3}{*}{$\begin{array}{l}\text { Value } \\
\text { - of } p\end{array}$} \\
\hline & \multirow[t]{2}{*}{$\mathrm{HR}$} & \multicolumn{2}{|c|}{$\mathrm{BP}$} & \multirow{2}{*}{$\begin{array}{c}\mathrm{ETCO}_{2} \\
{[\mathrm{mmHg}]}\end{array}$} & \multirow[t]{2}{*}{$\mathrm{SatO}_{2}[\%]$} & \multirow[t]{2}{*}{$\mathrm{HR}$} & \multicolumn{2}{|c|}{ BP } & \multirow{2}{*}{$\begin{array}{c}\mathrm{ETCO}_{2} \\
{[\mathrm{mmHg}]}\end{array}$} & \multirow{2}{*}{$\mathrm{SatO}_{2}[\%]$} & \\
\hline & & $\begin{array}{l}\text { Systolic } \\
{[\mathrm{mmHg}]}\end{array}$ & $\begin{array}{l}\text { Diastolic } \\
{[\mathrm{mmHg}]}\end{array}$ & & & & $\begin{array}{l}\text { Systolic } \\
{[\mathrm{mmHg}]}\end{array}$ & $\begin{array}{l}\text { Diastolic } \\
{[\mathrm{mmHg}]}\end{array}$ & & & \\
\hline 1 & 82.5 & 142.7 & 78.1 & - & 97.7 & 79.8 & 142.6 & 78.5 & - & 97.1 & $>0.05$ \\
\hline 2 & 87.6 & 142.2 & 78.0 & - & 99.1 & 84.5 & 141.2 & 80.8 & - & 98.7 & $>0.05$ \\
\hline 3 & 93.1 & 140.3 & 81.7 & - & 99.0 & 91.6 & 145.8 & 84.0 & - & 98.8 & $>0.05$ \\
\hline 4 & 83.3 & 130.0 & 76.2 & 37.9 & 98.5 & 81.2 & 142.1 & 84.4 & 36.2 & 98.3 & $>0.05$ \\
\hline 5 & 82.3 & 140.2 & 86.4 & 36.0 & 98.0 & 79.7 & 144.0 & 88.1 & 37.5 & 97.5 & $>0.05$ \\
\hline 6 & 84.3 & 139.4 & 85.3 & 37.5 & 97.8 & 79.7 & 142.4 & 87.2 & 38.6 & 97.2 & $>0.05$ \\
\hline 7 & 83.1 & 140.9 & 84.5 & 38.3 & 97.9 & 80.6 & 139.9 & 84.6 & 38.2 & 97.5 & $>0.05$ \\
\hline 8 & 80.5 & 141.5 & 82.1 & 37.6 & 98.9 & 81.1 & 143.0 & 85.0 & 37.9 & 98.0 & $>0.05$ \\
\hline 9 & 94.1 & 146.9 & 84.3 & - & 99 & 88.5 & 143.6 & 85.3 & - & 97.3 & $>0.05$ \\
\hline
\end{tabular}

Time: 1 - before anaesthesia, 2- passive oxygenation, 3 - endotracheal intubation, 4-immediately after intubation, 5-insufflation of $\mathrm{CO}_{2}, 6$ - during the gallbladder exteriorization, 7 -immediately before the end of anaesthesia, 8 - before awakening from anaesthesia, 9 -immediately after awakening from anaesthesia

Table II. Bispectral index (BIS) values

\begin{tabular}{|lccc|}
\hline Time & Group I & Group II & Value of $p$ \\
\hline Before anaesthesia & 96.5 & 96.5 & $>0.05$ \\
\hline Passive oxygenation & 96.8 & 97.3 & $>0.05$ \\
\hline Endotracheal intubation & 47.8 & 49.4 & $>0.05$ \\
\hline Immediately after intubation & 56.1 & 58.2 & $>0.05$ \\
\hline Insufflation of $\mathrm{CO}_{2}$ & 49.6 & 52.4 & $>0.05$ \\
\hline During the gallbladder exteriorization & 53.8 & 52.3 & $>0.05$ \\
\hline Immediately before end of anaesthesia & 57.6 & 59.2 & $>0.05$ \\
\hline Before awakening from anaesthesia & 68.4 & 70.6 & $>0.05$ \\
\hline Immediately after awakening from anaesthesia & 93.0 & 92.2 & $>0.05$ \\
\hline
\end{tabular}

with high-flow rate analgesia (Table II). Statistically significant mean differences of cerebral oximetry between the two groups do not attest to disturbance in supply and consumption of oxygen in central nervous system cells; hence they do not attest to superiority of one of the anaesthetization method over the other (Table III). Trends in oximetry values seem to be the key factor, and these were similar both for lowflow and high-flow rate anaesthesia.

\section{Discussion}

According to DeWall, insufflation of $\mathrm{CO}_{2}$ into the peritoneal cavity during laparoscopy and $\mathrm{CO}_{2}$ absorption by the peritoneal blood vessels leads to raised end-tidal $\mathrm{CO}_{2}$ concentration $\left(\mathrm{ETCO}_{2}\right)$. It reduces the cerebral vascular resistance, and increases cerebral blood flow and partial pressure of oxygen in the brain [7]. There were no changes in the trends of 
Table III. Mean values of cerebral oximetry (\%) for left $(\mathrm{L})$ and right (R) cerebral hemisphere

\begin{tabular}{|ccccccc|}
\hline Time & Group I & Group II & Value of $p$ & Group I & Group II & \multirow{2}{*}{ Value of $p$} \\
\cline { 2 - 3 } & $\mathrm{L}$ & $\mathrm{L}$ & & $\mathrm{P}$ & $\mathrm{P}$ & \\
\hline 1 & 65.3 & 65.2 & $<0.05$ & 73.0 & 72.4 & $<0.05$ \\
\hline 2 & 67.0 & 74.8 & $<0.05$ & 67.4 & 74.4 & $<0.05$ \\
\hline 3 & 71.6 & 77.0 & $<0.05$ & 71.2 & 77.6 & $<0.05$ \\
\hline 4 & 71.8 & 77.6 & $<0.05$ & 72.0 & 78.3 & $<0.05$ \\
\hline 5 & 67.2 & 73.2 & $<0.05$ & 68.1 & 73.8 & $<0.05$ \\
\hline 6 & 68.7 & 74.0 & $<0.05$ & 69.8 & 75.3 & $<0.05$ \\
\hline 7 & 70.2 & 76.2 & $<0.05$ & 71.0 & 77.2 & $<0.05$ \\
\hline 8 & 72.2 & 77.0 & $<0.05$ & 72.8 & 77.0 & $<0.05$ \\
\hline 9 & 74.1 & 78.5 & $<0.05$ & 74.6 & 79.1 & $<0.05$ \\
\hline
\end{tabular}

Time: 1 - before anaesthesia, 2 - passive oxygenation, 3 - endotracheal intubation, 4-immediately after intubation, 5-insufflation of CO2, 6 - during the gallbladder exteriorization, 7 -immediately before the end of anaesthesia, 8-before awakening from anaesthesia, 9 -immediately after awakening from anaesthesia

cerebral oximetry measurements in both groups observed during the study. It resulted from maintaining normocapnia by ventilation increase and placing patients head up. This reduced cerebral hyperaemia and presumably balanced the earlier described effect. It suggests that cerebral oxygen metabolism is constant during the $\mathrm{CO}_{2}$ insufflation and the lowflow rate anaesthesia is safe.

It is difficult to assess the sleep depth during general anaesthesia based on clinical symptoms alone $[8,9]$. Without objective measures and monitoring it is just an irrational notion that allows only subjective assessment of too shallow, too deep or adequate anaesthetization. Currently the most efficient method of sleep depth and sedation assessment is the bispectral analysis of mean frequency of electroencephalography (EEG) (bispectral index - BIS). It allows transformation of the EEG recording into the integral number in the range of 1-100. Its value decreases with the deepening of anaesthesia. Values of 40-60 characterize the sleep depth appropriate for anaesthesia, whereas the range of 60-80 increases the probability of intra-operative awakening and return of the anterograde memory [10]. Thanks to the numeric assessment of the anaesthetization's depth, control over the hypnotic effect of the anaesthetic drugs becomes objective and that reduces the risk of return of the patient's consciousness [11]. Incidents of intra-operative awakening of the patient occur with a frequency of $0.2-1.2 \%$ [12]. The BIS mon- itoring during general anaesthesia was associated with significantly fewer incidents of intra-operative awakening in comparison to a retrospective cohort of patients without such monitoring in the analysis by Ekman et al. [13]. Two multicentre studies demonstrated that it reduced the number of intra-operative awakening episodes by over $80 \%[13,14]$. It also allows administration of more precise, patient-tailored drugs according to their requirements. Medication administration in advance based on the BIS values prevents adverse reflexes of the circulatory system and motor response to the pain impulses connected with the operation [9, 15-17].

The results of the present study show that sevoflurane use in concentrations maintaining BIS values in the range of 40-60 provides adequate sleep depth during both modes of anaesthetization. High doses of sevoflurane efficiently decreased systemic blood pressure, electrical brain activity and cerebral blood flow, having little influence on cerebral oximetry at the same time. There were no intra-operative awakening episodes noted in either group. Similar observations in relation to different procedures were part of other studies $[18,19]$.

\section{Conclusions}

Use of both low-flow and high-flow rate general anaesthesia provided patients undergoing laparoscopic cholecystectomy proper oxygenation of the 
central nervous system, adequate depth of sleep and haemodynamic stability.

\section{References}

1. Głuszek S, Bonek Z. State of gallstone videosurgery in Świętokrzyskie Voivodeship. Videosurgery and Other Miniinvasive Techniques 2008; 3: 111-8.

2. Wirkowski A, Pesta W. Traps of laparoscopic cholecystectomy. Videosurgery and Other Miniinvasive Techniques 2008; 3: 179-85.

3. Modrzejewski A, Kurzawski M, Chęciński P, et al. Laparoscopic cholecystectomy during pregnancy. Videosurgery and Other Miniinvasive Techniques 2008; 3: 186-91.

4. Tempia A, Olivei MC, Calza E, et al. The anaesthetic conserving device compared with conventional circle system used under different flow conditions for inhaled anaesthesia. Anesth Analg 2003; 96: 1056-61.

5. Frederic J, Gerges MD, Ghassan E, Kanazi MD. Anesthesia for laparoskopy: review. J Clin Anesth 2006; 18: 67-78.

6. Sivaci R, Orman A, Yilmazer M, et al. The effect of low-flow sevoflurane and desflurane on pulmonary mechanics during laparoscopic surgery. J Laparoendosc Adv Surg Tech 2005; 15: 2.

7. de Waal EE, de Vries J, Kruitwagen CL. The effects of low-pressure carbon-dioxide pneumoperitoneum on cerebral oxygenation and cerebral blood volume in children. Anesth Analg 2002; 94: 500.

8. Ibrahim AE, Taraday JK, Kharash ED. Bispectral index monitoring during sedation with sevoflurane, midazolam and propofol. Anesthesiology 2001; 95: 1151-9.

9. Kerssens CH, Klein J, van der Woerd A, et al. Auditory information processing during adequate propofol anaesthesia monitored by electroencephalogram bispectral index. Anesth Analg 2001; 92: 1210-4.

10. March PA, Muir WW. Bispectral analysis of the electroencephalogram: a review of its development and use in anesthesia. Veterinary Anaesth Analg 2005; 32: 241-55.

11. Burrow B, Mc Kenzie B, Case C. Do anesthetized patent recover Better after bispectral index monitoring? Anesth Intensive Care 2001; 29: 239-45.

12. Baars Bernard J. The Brain Basis of a 'Consciousness Monitor.' A breakthrough in testing unconsciousness during anesthesia. Sci Conscious Rev 2002; 13: 2003.

13. Ekman A, Lindholm ML, Lennmarken C, Sandin R. Reductionin the incidence of awareness using BIS monitoring. Acta Anaesthesiol Scand 2004; 48: 20-6.

14. Myles PS, Leslie K, McNeil J, et al. Bispectral index monitoring to prevent awareness during anaesthesia: the B-Aware randomised controlled trial. Lancet 2004; 363: 1757-63.

15. Hans $\mathrm{P}$, Bonhomme $\mathrm{V}$, Benmansour $\mathrm{H}$, et al. Effect of nitrous oxide on bispectral index and $95 \%$ spectral edge frequency of the electroencephalogram during surgery. Anaesthesia 2001; 56: 998-1002.

16. Ropcke H, Konen-Bergmann M, Cuhls M, et al. Propofol and remifentanil pharmacodynamic interaction during orthopedic surgical procedures as measured by effects on bispectral index. J Clin Anesth 2001; 13: 198-207.
17. Lysacowski C, Dumont L, Pellegrini M, et al. Effects of fentanyl, alfentanil, remifentanil and sulfentanil on loss of consciousness and bispectral index during propofol induction of anaesthesia. $\mathrm{Br}$ J Anaesth 2001; 86: 523-7.

18. Chin KJ, Yeo SW. A BIS guided study of sevoflurane requirements for adequate depth of anaesthesia in casarean section. Anaesthesia 2004; 59: 1064-8.

19. Skaja D, Graff M, Karwacki Z. BIS monitoring during volatile anaesthesia for lumbal laminotomy. Anest Inten Terap 2006; 38: $72-5$. 